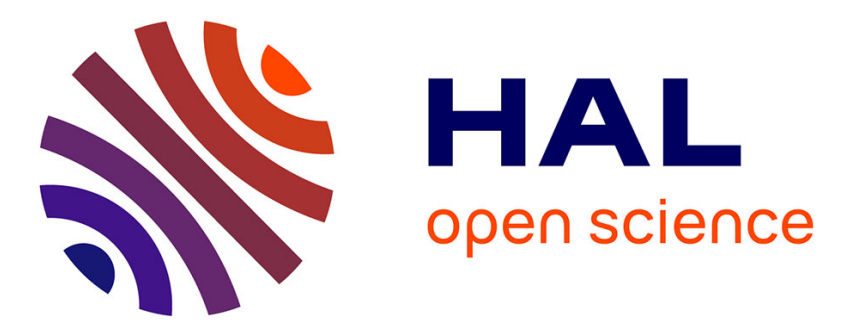

\title{
Comparison of ULF electric field recorded by ground-based stations in China and a low-altitude satellite
}

Rui Yan, Lanwei Wang, Michel Parrot, Xingguo Zhang, Zhe Hu

\section{- To cite this version:}

Rui Yan, Lanwei Wang, Michel Parrot, Xingguo Zhang, Zhe Hu. Comparison of ULF electric field recorded by ground-based stations in China and a low-altitude satellite. The European Physical Journal. Special Topics, 2021, 230 (1), pp.179-195. 10.1140/epjst/e2020-000250-9 . insu-03157245

\section{HAL Id: insu-03157245 \\ https://hal-insu.archives-ouvertes.fr/insu-03157245}

Submitted on 23 Apr 2021

HAL is a multi-disciplinary open access archive for the deposit and dissemination of scientific research documents, whether they are published or not. The documents may come from teaching and research institutions in France or abroad, or from public or private research centers.
L'archive ouverte pluridisciplinaire HAL, est destinée au dépôt et à la diffusion de documents scientifiques de niveau recherche, publiés ou non, émanant des établissements d'enseignement et de recherche français ou étrangers, des laboratoires publics ou privés. 


\title{
Comparison of ULF electric field recorded by ground-based stations in China and a low-altitude satellite
}

\author{
Rui Yan ${ }^{1, a}$, Lanwei Wang ${ }^{1}$, Michel Parrot ${ }^{2}$, Xingguo Zhang ${ }^{1}$, and Zhe $\mathrm{Hu}^{1}$ \\ ${ }^{1}$ Institute of Crustal and Dynamics, China Earthquake Administration, 100085 Beijing, \\ P.R. China \\ ${ }^{2}$ University of Orléans, LPC2E/CNRS, Orléans 45071, France
}

Received 2 October 2020 / Accepted 7 October 2020

Published online 19 January 2021

\begin{abstract}
The correlation and synchronization between ground-based and space-based electric field in calm period, is the basis for a comprehensive study of earthquake monitoring. However, it is difficult to study their relevance because of large dissimilarities on data records. The DC-ULF electric field recorded by the DEMETER satellite and the geo-electric field observed in ground-based stations in China were comprehensively analyzed in this paper. The results show that the ionospheric electric field after removing the additional electric field caused by the satellite motion in the magnetic field has a stable annual variation trend; both the annual variation trend and the amplitude of ionospheric electric field above different locations in China are similar. The synchronous, corresponding and similar significant annual variation trends of both ionospheric electric field and geo-electric field in the same direction and with same frequency were found above some locations. The trend displays higher value in summer and lower value in winter. The Sq (Solar quiet) current system is the main source for these phenomena. It is noticed that the shapes and amplitude of geoelectric field for different stations are different, largely due to their individual underground layer conductivity, water level and so on. It is of great significance to explore the correlation and consistency between ground-based and space-based data in order to recognize the anomalies related to the seismic activity and to understand the LAI (Lithosphere-Atmosphere-Ionosphere) coupling mechanism.
\end{abstract}

\section{Introduction}

Electric field perturbations possibly connected with seismic activity is a matter of great concern. There are many reports about this study using the data from groundbased measurements [1-6] and data from space-based satellite experiment [7-11]. A joint analysis of variation related to seismic activity using these two kinds of data have also been studied in recent years [12-16]. They found that some electromagnetic anomalous phenomena appeared on the ground as well as in the ionosphere

a e-mail: yanxiaoxiao_best@163.com 
at a rough same time. They also pointed out that studying a number of earthquakes using ground-based and satellite data simultaneously can be a crucial and effective way of investigating the Ultra-Low-Frequency/Extremely Low Frequency (ULF/ELF) electromagnetic anomaly triggered by the seismic activity.

These anomalous phenomena are considered as the manifestation for the existence of a lithosphere-atmosphere-ionosphere (LAI) coupling [17,18]. As for this LAI mechanism, two main models are currently considered. One is the Electro Motive Force (EMF) model which is based on the assumption that ionization of lower atmosphere (mainly due to radon) leads to the seismic-related electric field formation in the ionosphere [19]. Another model is related to air ionization at rock surfaces, which is a massive air ionization prior to major earthquakes which increases the electrical conductivity in the air column and may cause ionospheric perturbations because there are conditions under which the air ionization at the ground-to-air interface produces exclusively positive airborne ions. If the atmosphere becomes laden with positive ions, it will introduce an electrostatic (Coulomb) perturbation that can be expected to affect the vertical E field which is a part of the global electric circuit. Then, it will affect the ionosphere [20]. So there are a lot of works at this time to study the anomalous phenomena related to earthquakes and to try to understand their generation mechanism

In this work, it is very meaningful to study the electric field characteristics during calm period synchronously. The study of space- and ground-based electromagnetic observational data and their correlation can help researchers to understand the LAI coupling. Especially the basic characteristics of space- and ground-based data and their correlation during the period without events such as earthquakes, storms etc. can help us to understand and recognize the characteristics of these data during the period with events. It is also of great scientific significance for comprehensively utilizing the satellite and ground electromagnetic monitoring data for earthquake monitoring research [21]. However, it is difficult to study their relevance because of large dissimilarities on data records. Very few papers have been published on this topic.

Only some studies on the characteristics of these two kinds of data during calm period separately can be found. About the geo-electric field characteristics, Mogi et al. [22] have studied the short-term and the long-time variation of electric field. Shortterm electric field variations were found to correspond mainly to geomagnetic activity, while long-term variation was mostly gradual shift and was clearly uncorrelated to precipitation and to ground water level variations. Ye et al. [23] studied the spectrum characteristics of geo-electric diurnal variation based on data from stations in China. This study showed that in geo-electric diurnal variation, the amplitude of the $12 \mathrm{~h}$ semidiurnal wave is the largest. Cui et al. [24] has studied the time and frequency characteristics of the geo-electric field diurnal variation along two longitude chains and two latitude chains and found the same conclusion with Ye [23]. Concerning the characteristics of the ionospheric electric field during calm period, Yu et al. [25-27] studied the yearly variation of ionospheric electric fields at mid- and low-latitudes under the condition of low solar and quiet geomagnetic activities with a theoretical model of ionospheric electric fields. Results revealed that the coupled electric field would show a pronounced semi-annual variation due to the "coupling effect" along the magnetic field lines between two hemispheres, whereas the uncoupled electric field have an annual variation in respective hemisphere.

The study in this paper closely follows a study by the author in 2013 [21], where research on the characteristics and relationship using geo-electric field observed in two stations and corresponding ionospheric electric field measured by DEMETER were done. Their results showed that during the night, the annual trends of electric field from space and ground-based observational data have exhibited correlation and 
synchronization every year. In order to research whether or not there is a certain relationship between the ionospheric electric field and geo-electric field in a wider area; we extend the data set to all over China. We also update the data processing method and selected the north-south (NS) direction both in geo-electric field and ionospheric electric field as the main direction in the research. Then we evaluate the correlation between them. Data source and selection is presented in Section 2. We will introduce data processing method in Section 3. Section 4 presents results. They are discussed in Section 5 and summarized in Section 6.

\section{Data source and selection}

\subsection{Data source}

The ground-based electric field data are recorded by the instrument ZD9A in ground stations. ZD9A is an electric field detector which has been developed in China and installed in many stations $[28,29]$. The frequency band is $0-0.1 \mathrm{~Hz}$ and the sampling rate is $1 \mathrm{~Hz}$. Horizontal component, north-south (NS) and west-east (WE) directions of geo-electric field have been registered, with a set of orthogonal configurations. Each of them is composed of two non-polarized solid state electrodes with spacing of $300 \mathrm{~m}$ or $400 \mathrm{~m}$, and buried $3-4 \mathrm{~m}$ below the ground surface. At present, geo-electric field observations related to earthquakes in China are mostly fixed-point measurements, with 85 stations throughout the country [5,16,23,24].

The space-based electric field data from the French spacecraft DEMETER have been used. DEMETER was a microsatellite launched in June 2004 and stopped in 2010. Its orbit was circular and quasi sun-synchronous (10.30 and $22.30 \mathrm{LT}$ ) with an altitude of about $700 \mathrm{~km}$ and an inclination of $98^{\circ}$. The altitude was changed to about $660 \mathrm{~km}$ in December, 2005 [30]. We have focused on the analysis of electric field data measured by the ICE instrument. There are four stacer booms used by the ICE experiment, which have a length of $4 \mathrm{~m}$. The probes $E 1$ and $E 2$ are deployed parallel to the satellite $Y$-axis, i.e. perpendicular to the satellite $X Z$ plane that is the orbital plane for the nominal attitude of the satellite. The probes E3 and E4 are deployed at $45^{\circ}$ from the $X$-axis, which is the nadir direction, and at distances of about $15 \mathrm{~cm}$ on both sides of the satellite $X Z$ plane. All 3 components of electric field in satellite coordinate are $E x$ (upward), $E y$ (vertical to satellite orbital plane), and $E z$ (opposite to the satellite direction) $[31,32]$. In order to keep the same frequency range for the two sets of electric field data, we select the DEMETER DC/ULF (0-15 Hz) data. The signals are sampled at $39.0625 \mathrm{~Hz}$, and the time resolution is $6.55360 \mathrm{~s}$. The data unit is in $\mathrm{mV} / \mathrm{m}[31,32]$. We can get the data of the $E 1, E 2, E 3$, and $E 4$ probes, and the electric field $E x, E y$, and $E z$ in the satellite coordinate system.

\subsection{Data selection}

The stations in China are not evenly distributed. There are fewer stations in the west due to geological conditions. In order to study the geo-electric field in China, it is better to obtain data in the stations which have fixed distance intervals and cover the whole country. On this basis, considering the data quality and the distribution of stations available all over China, geo-electric field data observed from 30 stations have been selected among the total 85 stations. The latest digital ZD9A instruments have been deployed at most of stations in China since the second half of 2007. We have firstly analysed the annual variation trend of the observed data. It shows that only data from 5 stations display obvious good regular annual variation trends. For 


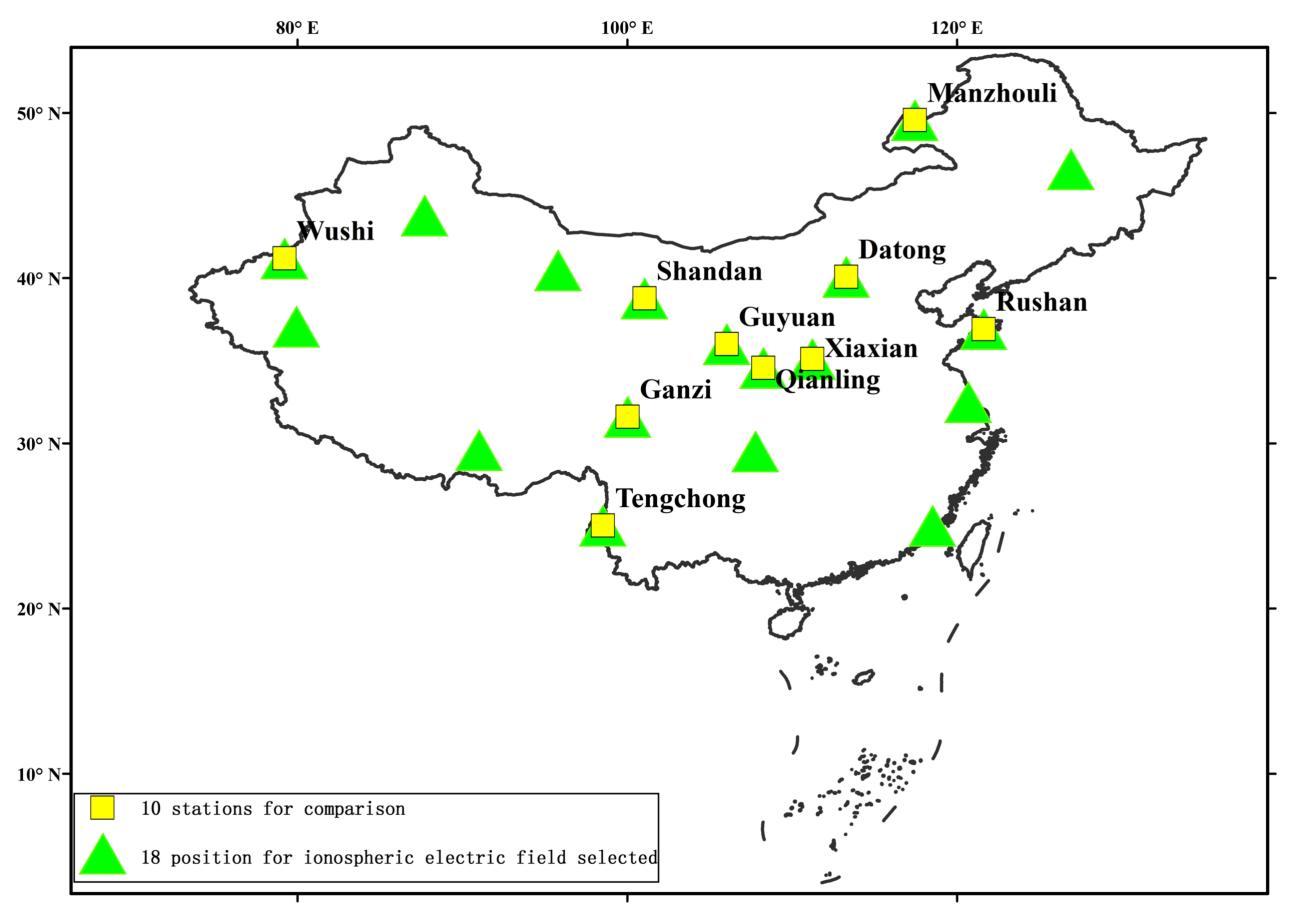

Fig. 1. Distribution map of geo-electric field stations in China.

9 stations, after removing the interference data [4], a rough annual variation trends can be seen. So for these 30 stations selected there are annual variation trends in 14 stations whereas for other most stations, there are no regular variation trends. Considering the observation periods of these two kinds of data we obtained data of two complete years (from 2008 to 2009).

All ionospheric electric field data in the whole territory of China have similar obvious annual change trend, the correlation between the two kinds of observation data is completely dependent on whether the geo-electric field data has annual change trend or not. If there is no annual trend in the geo-electric field, obviously, it is not meaningful to compute the correlation coefficients of these two kinds of data. It is better to search correlation of data with good and rough annual trend in 14 stations. But for 4 stations. (Guazhou, Songshan, Jiayuguan, Chengdu), the data sets are not complete for 2008 and 2009. So finally, we have selected geo-electric field data in the remaining 10 stations (yellow squares in Fig. 1) with both, good and roughly annual variation trend, and corresponding ionospheric electric field data, to carry out correlation research.

There is no obvious large variation of the electric field in the ionosphere inside a large area, and we will have the same revisited orbits for several nearby stations (revisited orbits are the orbits passing by the same sub-satellite point, which means these revisited orbits are roughly above the same location). So we need not to process ionospheric electric field corresponding to all 30 geo-electric field stations. According to the different annual trends of the geo-electric field in these 30 stations, and considering the station positions for a better distribution of observation stations over China, the night time ionospheric electric field corresponding to a selection of 18 stations (green triangles in Fig. 1) among the 30 stations was processed and analysed in order to compare their different annual variation trends. These 18 stations are corresponding to 5 stations with good annual trend, 6 stations with rough annual 
trend and 7 stations with no annual trend, including the positions corresponding to the above 10 selected stations. From these data above 18 locations, we can get the characteristics of ionospheric electric field all over China. During the DEMETER operation period from 2004 to 2010, only data observed in 2006-2009 were selected, because the altitude of DEMETER was adjusted from $710 \mathrm{~km}$ to $660 \mathrm{~km}$ in midDecember 2005 [33] and the sun spot in 2009 is lowest in the solar cycle whereas the one in 2010 begin to ascend. So for each station, all revisited orbits during 2006-2009 are used, similar to the selection described by Yan et al. [21].

We have focused on all data during nighttime with $\mathrm{Kp}$ index less than 3 in order to avoid perturbation by the solar activity.

\section{Data processing}

\subsection{The processing of electric field in ionosphere}

In order to comprehensively compare the space-based and ground-based electric fields, we should try our best to get similar parameters for these two kinds of observations. For the ionospheric electric field registered from DEMETER, there are 4 processing steps as follows.

(a) The data are transformed from the satellite coordinate system to the geographic coordinate system firstly. The data in the Ez direction which is identical to the NS direction of the geo-electric field are selected. Then we designed a low-pass filtering to extract the frequency band of $0-0.1 \mathrm{~Hz}$ from the DC-ULF $(0-15 \mathrm{~Hz})$ ionospheric electric field so that the space- and ground-based electric fields is consistent as much as possible in direction and in frequency bands.

(b) We need to calculate the additional electric field caused by the motion of the satellite across the Earth's geomagnetic field [31,34]. The additional electric field is in a geographic coordinate system, so data in Ez direction (corresponding to NS direction) is also selected. The time resolution of additional electric field is 30 seconds and then it is interpolated at the resolution of the original data.

(c) The temporal sequences of ionospheric electric field corresponding to each station are obtained. Firstly, the data point A which is nearest to the station position in every corresponding revisited orbit is found. Then we select data within $100 \mathrm{~km}$ range around point $\mathrm{A}$ and calculate the average value of them. The reasons for selecting $100 \mathrm{~km}$ are as follows: DC/ULF electric field signals are sampled at $39.0625 \mathrm{~Hz}$, and there are 256 points per $6.5536 \mathrm{~s}$. We have selected two sets of DC/ULF electric field data of about $13 \mathrm{~s}$, and, as the satellite velocity is $7.8 \mathrm{~km} / \mathrm{s}$, this corresponds to a distance of $100 \mathrm{~km}$ where we assume that there is no obvious variation for electric field in the ionosphere. The averaged data can remove the small variation and, then can reflect changes above that area.

(d) The average values of all successive revisited orbits are then obtained. Because there is only one revisited orbit every 16 days (2006 Jun, 2008) or 13 days (July, 2008 2009), and the revisited orbits were gradually changing from 2008, so the time resolution is not fixed. Only several tens of average values can be acquired during one year, and there are about two data points per month (Fig. 2).

(e) In order to decrease the influence of long-term variation of solar activity, we have eliminated the linear trend of temporal sequences using a least-squares fit (Fig. 3).

(f) Then we got the fitting line of these time series for each year using a Fourier approximation (Fig. 4). 


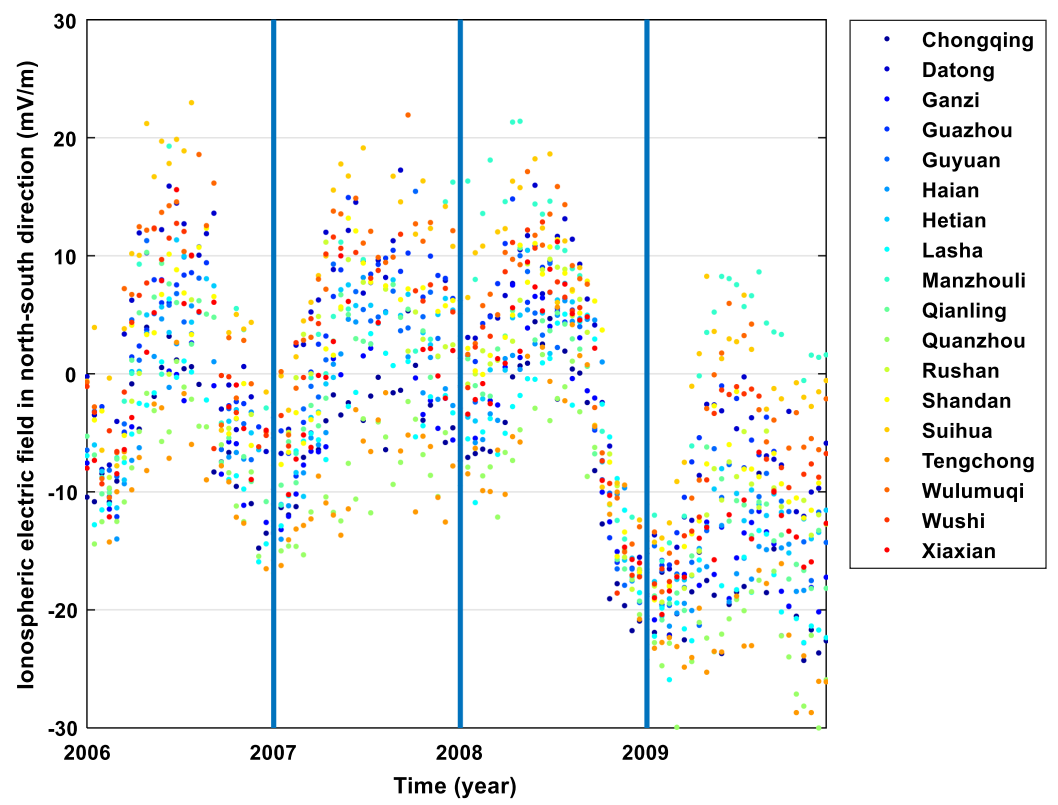

Fig. 2. Temporal sequences of the ionospheric electric field in NS direction of geographic coordinate system during 2006-2009. The blue vertical lines separate the different years. Data corresponding to different stations are plotted with different colors. The $X$-axis represents the time (year) whereas the $Y$-axis shows the amplitude of the ionospheric electric field $(\mathrm{mV} / \mathrm{m})$.

\subsection{The processing of geo-electric field}

Interference data refers to abnormal changes which are caused by the observation process itself, which includes non-natural changes such as single point jump, step change, and periodic change. By removing them, the obvious unreasonable observation data can be distinguished and eliminated. Then the observation data that can truly reflect the actual situation of each station can be obtained [4]. So the interference data should be removed from the geo-electric field observation data firstly. There are different interference cases for different stations, so no uniform standard can be used to remove interference data for different stations. For different interferences, we adopt different methods. We remove the single jump point directly; for step change, after checking these interference reasons, we first remove them directly, and according to the data before and after them, the data in this range are fitted and then added into the data set; and in case of periodic change, a filter is designed to remove them.

A night time (20:00-24:00) temporal sequence of daily average in each station should be generated, which correspond to the selected revisited orbits time of DEMETER.

Finally, the geo-electric field data will drift unsteadily because of unsteady of electrodes [35], similar to ionospheric electric field data, the linear trend caused by electrodes drift is also removed from the time series using a least-squares fit.

\subsection{Correlation calculation}

For the correlation between geo-electric field and ionospheric electric field, we focused on the geo-electric field data with obvious annual variation trends in the 10 stations 


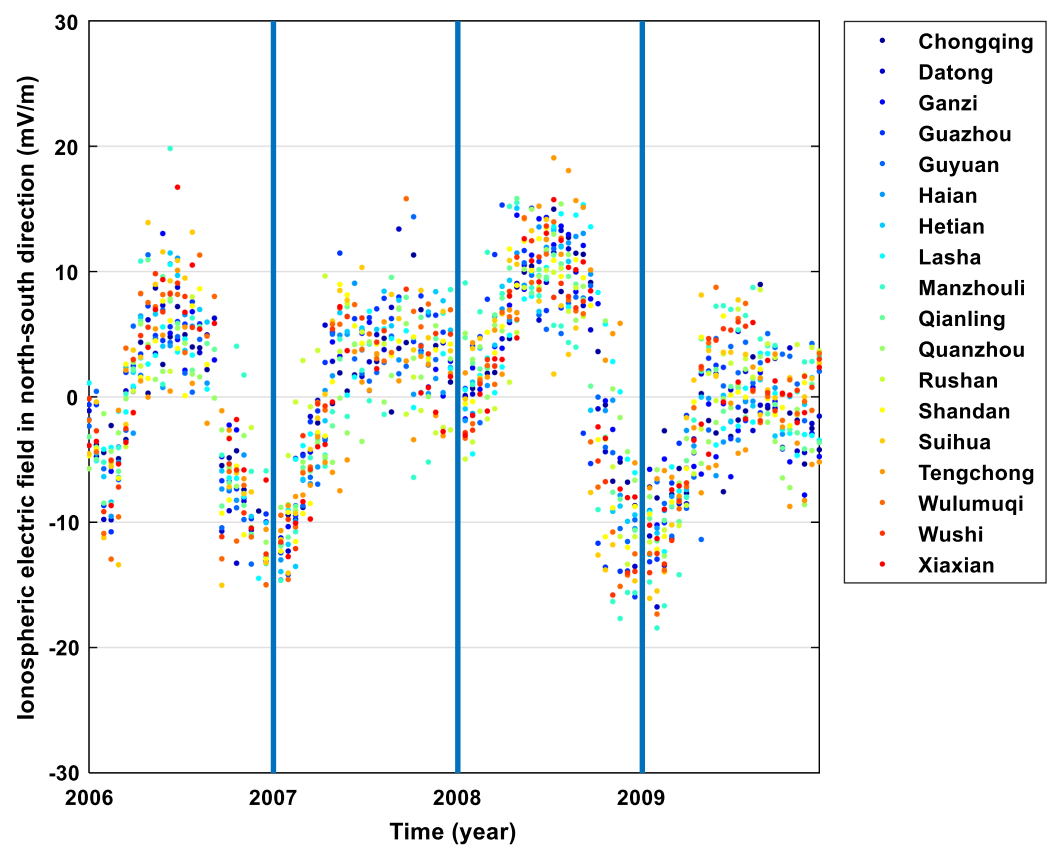

Fig. 3. Same temporal sequences as in Figure 2, but after removing the linear trend.

(purple triangles in Fig. 1) and the corresponding ionospheric electric field. The common observation periods of the two kinds of data are 2008 and 2009. The scatter plot and a linear regression model " $f(x)=a+b x$ " are used to find whether there is correlation (Fig. 6). The correlation coefficients (Tab. 1) are calculated by the equation (1).

$$
R(X, Y)=\frac{\operatorname{Cov}(X, Y)}{\sqrt{\operatorname{Var}[X] \operatorname{Var}[Y]}}
$$

In equation (1), for each station, $\mathrm{X}$ is the temporal sequence of the geo-electric field in 2008 and 2009, $\mathrm{Y}$ is the temporal sequence of the corresponding ionospheric electric field, and the length of $\mathrm{X}$ and $\mathrm{Y}$ temporal sequences are identical. But for different stations, the length is a little bit different.

\section{Results}

Figure 2 shows the temporal sequences of data in geographic NS direction of the ionospheric electric field corresponding to 18 stations selected during 2006-2009, which are the results of the processing explained in Section 3.1d. The points of different colours are related to the 18 stations (green triangles in Fig. 1). As seen in Figure 2, there is similar annual variation trend of ionospheric electric field corresponding to the 18 stations. During one year, the amplitude of ionospheric electric field is higher in summer and lower in winter. For the different years, the annual variation trend is stable and similar, but the amplitude which is between $-30 \mathrm{mV} / \mathrm{m}$ and $20 \mathrm{mV} / \mathrm{m}$ is not the same. The amplitude in 2009 is lower than in the other years.

Figure 3 also shows the same temporal sequences as in Figure 2, but the linear trend has been removed. Comparing to Figure 2, characteristics are consistent, however, the amplitude difference between 2009 and other years is weakened, and the amplitude range of each year is reduced. 




(a)

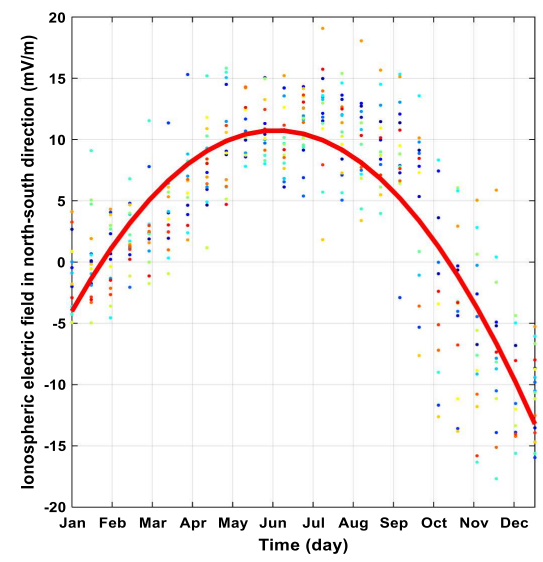

(c)

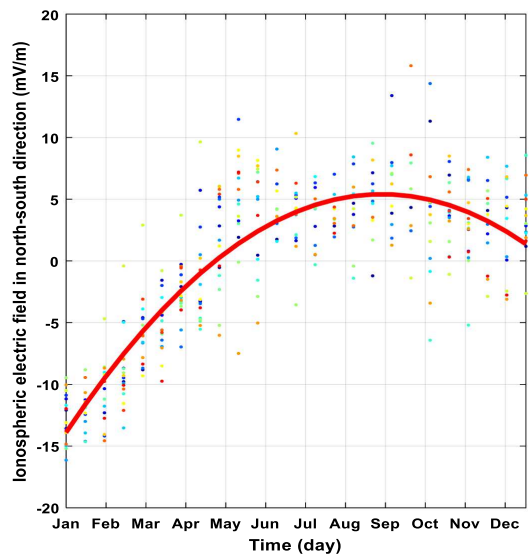

(b)

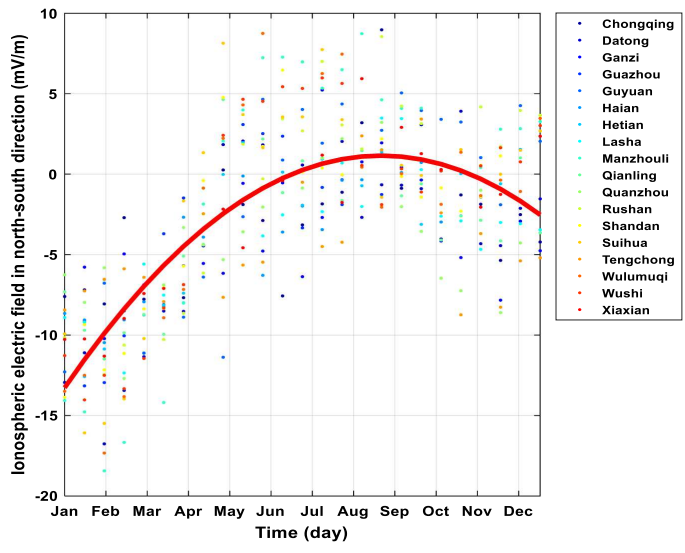

(d)

Fig. 4. The same temporal sequences as in Figure 2, but displayed in different years. The red smoothed line is the fitting line of temporal sequences. (a) data in 2006, (b) data in 2007, (c) data in 2008, (d) data in 2009.

Figure 4 shows the temporal evolution characteristic of the ionospheric electric field year by year which is underlined by a fitting line. The temporal sequences in Figure 4 are similar to the ones in Figure 3, but are displayed in different years. It is obvious that the annual variation characteristic is similar to sinusoidal (Fig. 4). We can also get the evolution model of temporal sequences in one year. The basic model of temporal evolution in each year is given by the equation (2). The coefficients $(a, b, n$, and $c)$ will change with observations data in different years.

$$
f(X)=a+b * \sin (n * X+c)
$$

In order to avoid a possible effect from electrode floating potential $[22,36]$, we study the correlation between ionospheric electric field and geo-electric field using the temporal sequences after removing the linear trend. The temporal sequences of the two kinds of electric fields in NS direction during 2008-2009 are shown in Figure 5 using double coordinates because of the huge difference of magnitude between them. The $Y$-axis in left side is ionospheric electric field (unit, $\mathrm{mV} / \mathrm{m}$ ) while the $Y$-axis in the right side is geo-electric field (unit, $\mathrm{mV} / \mathrm{km}$ ). Figure $5 \mathrm{a} \sim \mathrm{j}$ are corresponding to 


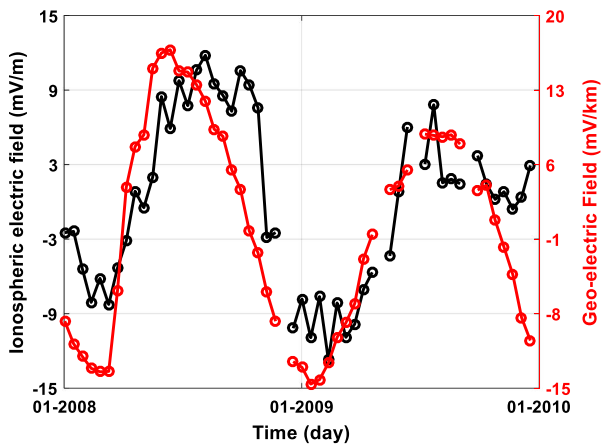

(a)

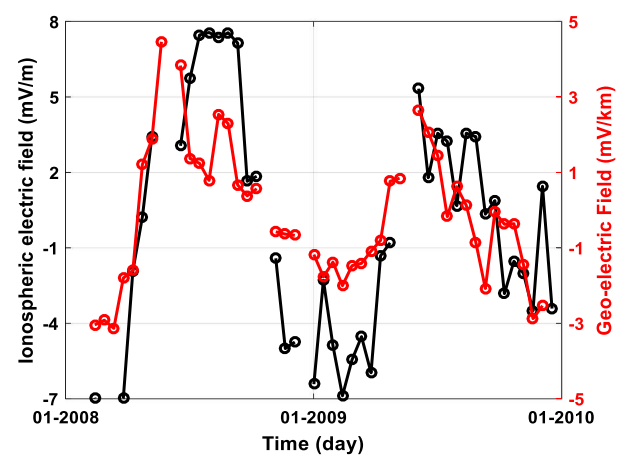

(c)

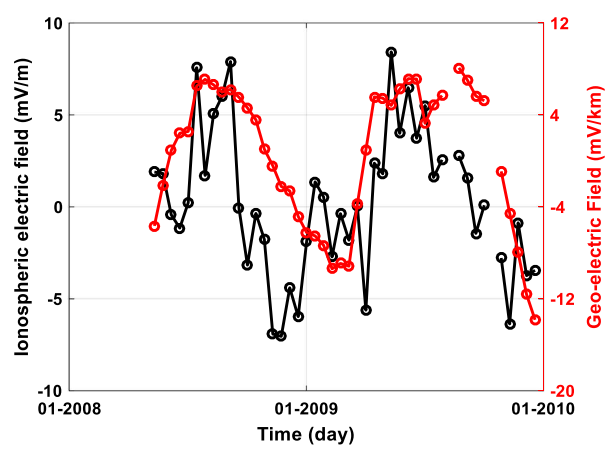

(e)

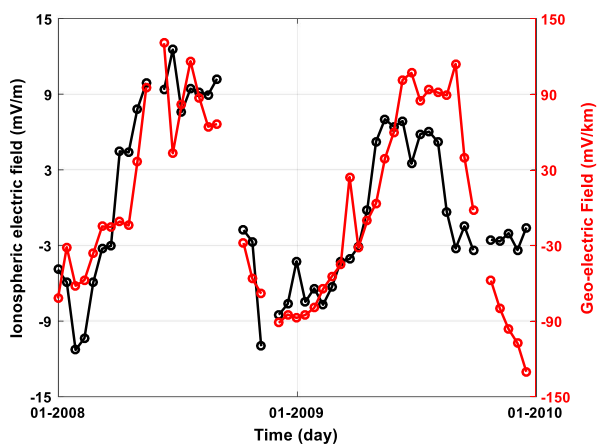

(b)

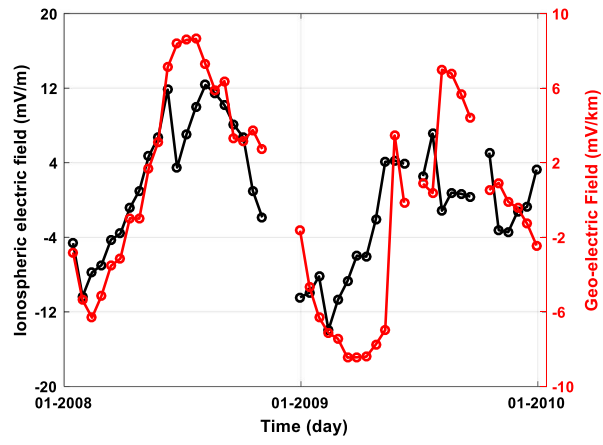

(d)



(f)

Fig. 5. The temporal sequences of electric field in NS direction obtained from space- and ground- based observation during 2008-2009 after removing the linear trend for different stations. (a) Shandan, (b) Wushi, (c) Qianling, (d) Datong, (e) Guyuan, (f) Tengchong.

different stations. It can be seen directly that the two kinds of data have very similar annual variation characteristics, which looks like a half sinusoidal curve.

Figure 6 indicates the results of scatter plot and regression analysis. Similar to Figures 5 and $6 \mathrm{a} \sim \mathrm{j}$ are also corresponding to different stations. The red line is the regression line in each case. The " $\mathrm{R}$ " is the correlation coefficient. The function " $f(x)=a+b x "$ is the regression model for each data set. In Figure 6, an obvious linear correlation between two kinds of data is found. For data at different positions, the regression models are nearly similar. 


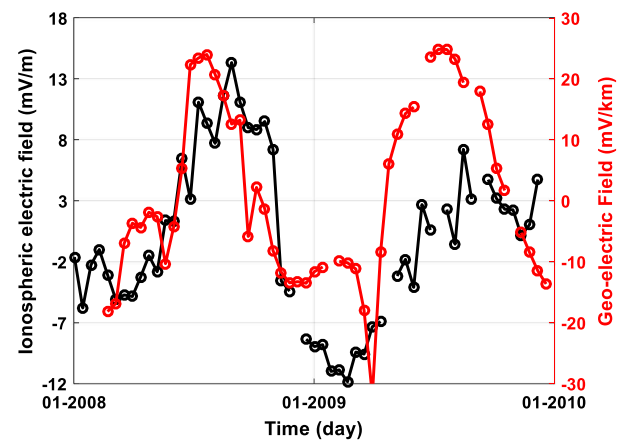

(g)

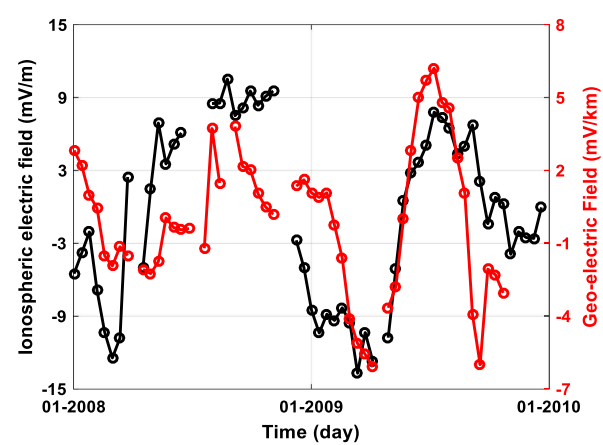

(i)

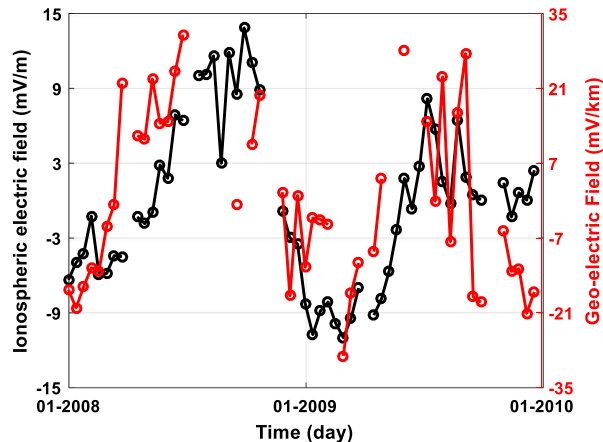

(h)

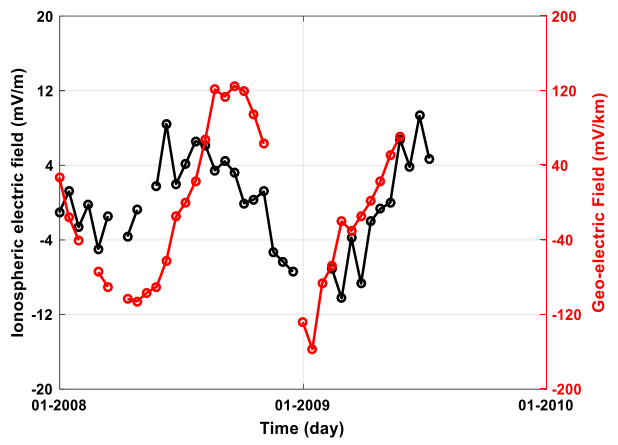

(j)

Fig. 5. continued.

Table 1 gives the list of the correlation coefficients of the corresponding data from space- and ground-based observation in the 10 positions selected in this study. We can find that after removing the trends from ground-based and space-based data, the correlation coefficients of data corresponding to the 5 stations with good, annual variation are good, which in 4 stations are more than 0.7 . For the 5 stations with annual variation most of the correlation coefficients are more than 0.5 (Tab. 1).

\section{Discussions}

From these analyses, the data of ionospheric electric field in different locations all over China showed the nearly same annual variation trends (Figs. 2 and 3). The amplitudes in different locations and during different years are also very similar. It should be noted that the amplitude of data in 2009 is slightly lower than data in the other three years. In general, for the ionospheric electric field in China, we can get the fixed annual variation model of approximate a half sinusoidal for each year (Fig. 4), although the coefficients are different in different years. This type of annual variation trend (red lines in Fig. 4) is consistent with the results of the annual variation characteristics of the ionospheric electric field studied by $\mathrm{Yu}$ et al. [25-27].

According to the statistics results, there are different trends of geo-electric field every year in many stations. Only in some stations, there are similar or same annual variation characteristics with ionospheric electric field. The amplitudes of data both with and without annual variation trends are also different depending on cases. Zhang et al. [16] thinks that the differences in geo-electric field amplitude and shapes 


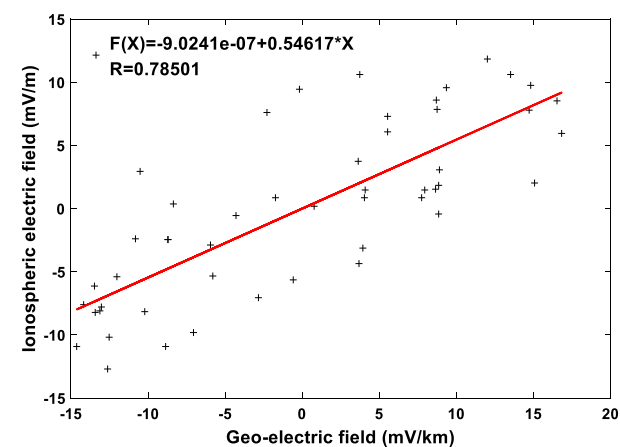

(a)

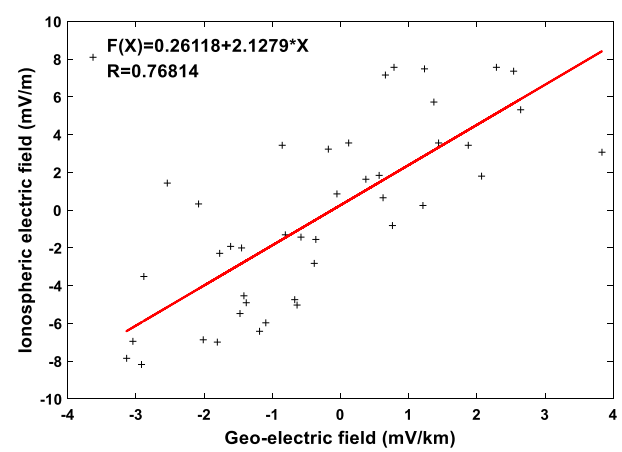

(c)

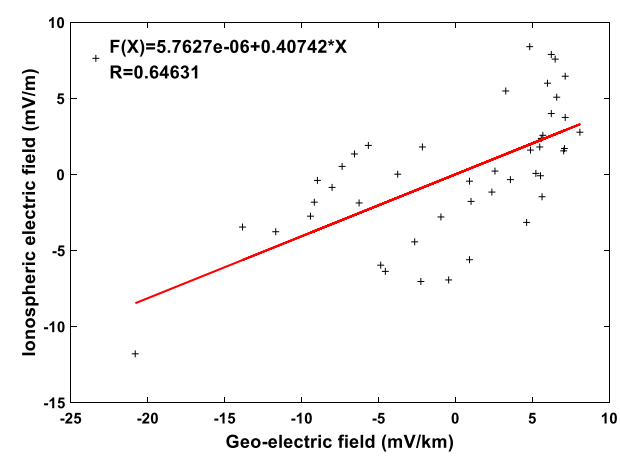

(e)

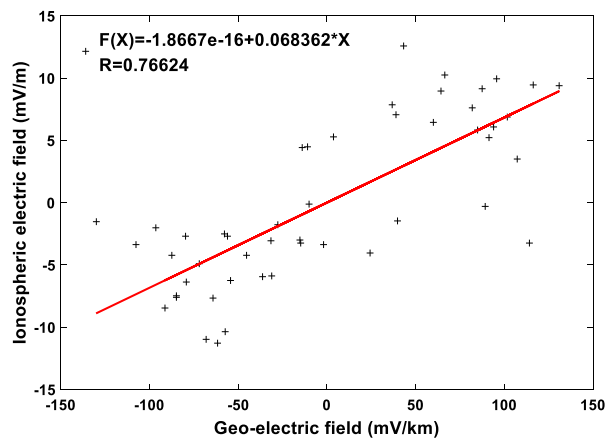

(b)

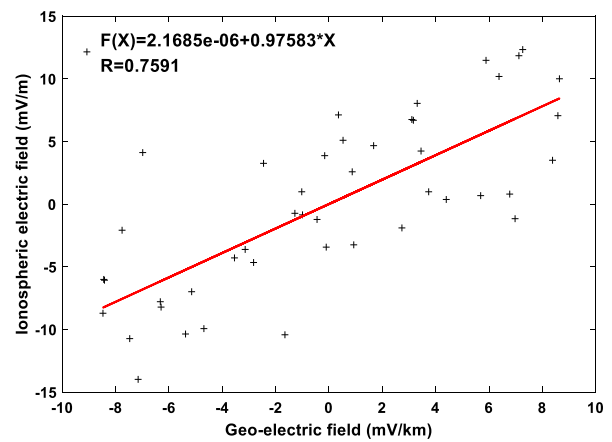

(d)

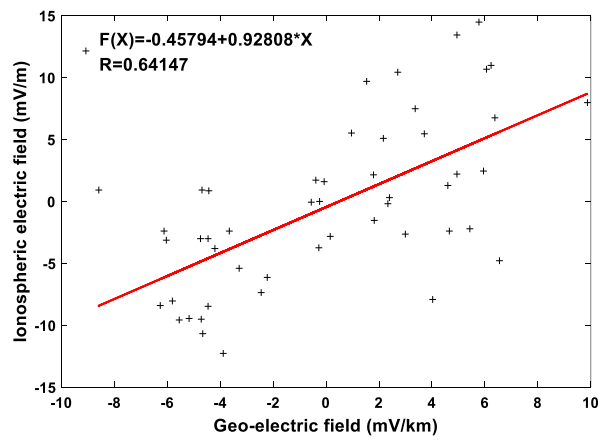

(f)

Fig. 6. The scatter plot of the same temporal sequences as in Figure 5 . The red line is the linear regression line. " $\mathrm{R}$ " is the correlation coefficient (see text). " $F(x)=a+b x$ " is the regression model for each data set (see text). (a) Shandan, (b) Wushi, (c) Qianling, (d) Datong, (e) Guyuan, (f) Tengchong, (g) Xiaxian, (h) Rushan, (i) Manzhouli, (j) Ganzi.

between different stations and among ground observing data reflect the different response process at stations with different underground electromagnetic structures and the response mechanism to current system in lithosphere. Li et al. [36] studied the geo-electric field observed at three stations in the Shanghai area and found that data in even very close three stations can vary greatly. They pointed that the huge differences of curve shape, amplitude and phase are caused by different electrical properties under the stations. The different laying way of the electrode, the different distance between the electrodes are other reasons, which is also mentioned by Mogi 


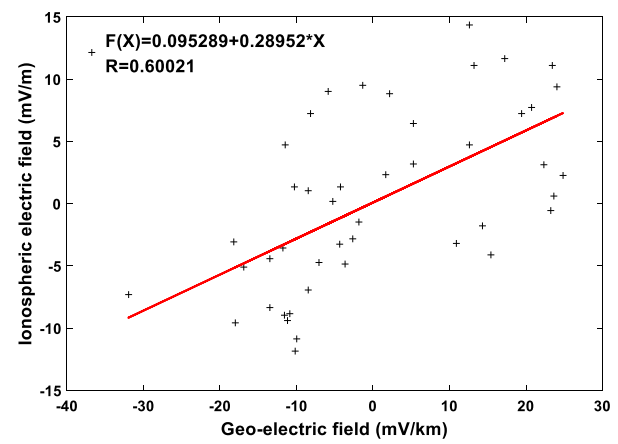

(g)

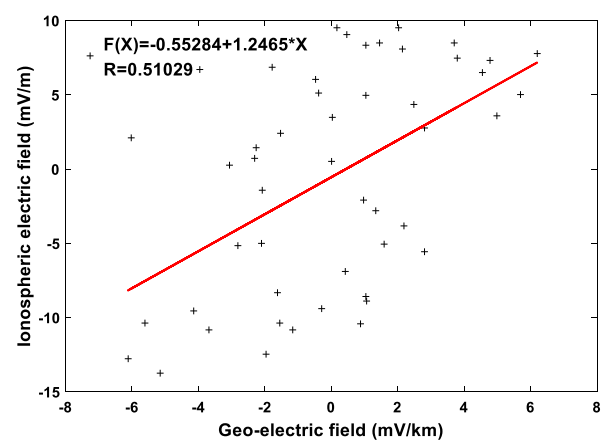

(i)

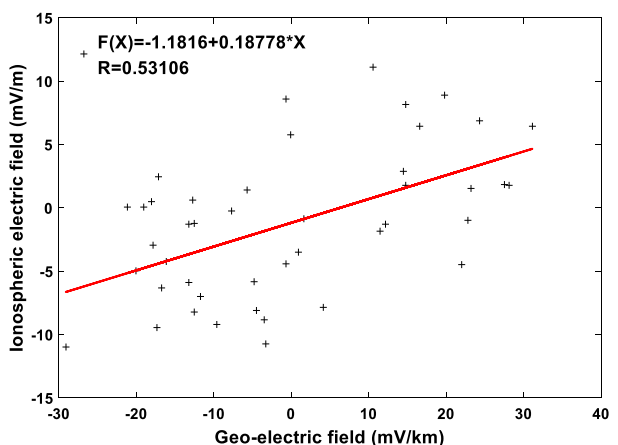

(h)

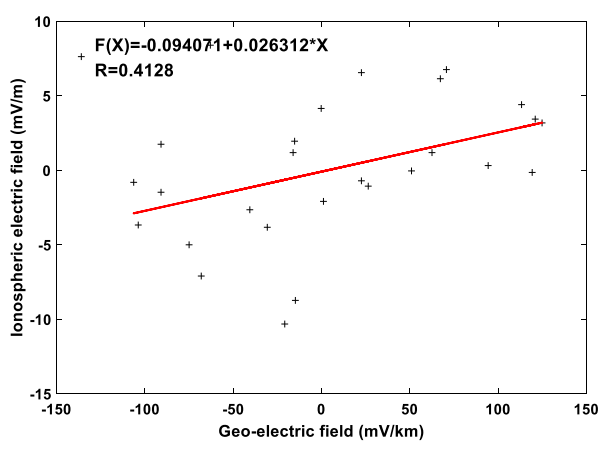

(j)

Fig. 6. continued.

et al. [22]. Tan et al. [37] think rock structure, the quaternary sediments, fracture and the bedrock, water content and permeability of rocks, tectonic activity, and other factors also affect the waveform of spontaneous electric field. So the amplitude and shape of data in different stations may be different due to the local Earth surface, the underground layer conductivity, and also the electrode contamination.

For the geo-electric field with annual variation trend in some stations, similar or nearly same annual variation characteristics of electric field both from space-based and ground-based measurement can be found (Fig. 5). A remarkable result is that although the geo-electric field variations are slightly different for these ground-based stations, the ionospheric electric fields measured by DEMETER above these stations well follow same variations. We also calculated the correlation coefficients of the two kinds of electric field and found that the correlation coefficients are good (Fig. 6 and Tab. 1). If we only consider the annual variation trend, there is a good correlation between the geo-electric field and ionospheric electric field for in these stations. This good correlation cannot be explained by the mechanism of LAI coupling. The study in this paper concerns electric field under normal conditions but in case of seismic activity, it could explain why the electric field induced in the lithosphere-atmosphere could propagate up to the ionosphere and trigger ionospheric perturbations [7,38-42].

In this section, we try to explain why there is a synchronous, corresponding and similar significant annual variation trend between electric field observed both on ground and in space. Sorokin and Hayakawa [17] find that there is no static electric field of lithospheric origin in the ionosphere. So the annual variation trend of these two kinds of electric field is not caused by source from lithosphere. It is probably from outside the Earth. The generator process theory holds that: an induced electric field is generated by a neutral wind dragging plasma and cutting magnetic field; at 
Table 1. The List of the correlation coefficients of the corresponding data from space- and ground-based observations.

\begin{tabular}{llll}
\hline & Positions & Correlation coefficient & Slope \\
\hline 1 & Shandan & 0.79 & 0.55 \\
2 & Wushi & 0.77 & 0.07 \\
3 & Qianling & 0.77 & 2.1 \\
4 & Datong & 0.76 & 0.98 \\
5 & Guyuan & 0.65 & 0.41 \\
6 & Tengchong & 0.64 & 0.93 \\
7 & Xiaxian & 0.60 & 0.29 \\
8 & Rushan & 0.53 & 0.19 \\
9 & Manzhouli & 0.51 & 1.25 \\
10 & Ganzi & 0.41 & 0.03 \\
\hline
\end{tabular}

the same time, due to the spatio-temporal unevenness of ionospheric conductivity, charge accumulation occurs, thus forming a polarized electric field, which produces observable plasma drift in the ionospheric $F$ region. This is the main component of the ionospheric electric field at low and medium latitudes. In the high latitudes, besides electric field caused by generator process, electric fields from the magnetosphere account for a considerable proportion of the electric field. The generator process theory cannot explain ionospheric electric field completely in the high latitudes. However, in the middle and low latitudes far away from the polar region, the influence from the magnetic layer is generally very small, so the generator theory can be applied well [43]. So the widely accepted generator process is a major source of ionospheric electric field in the middle-low latitudes and the equatorial regions. This process has been described in detail in many previous works [44-46]. The electric field and current systems mainly include the Sq (Solar quiet) current system which is the current system that generates the sun day variation of the quiet solar geomagnetic field and the equatorial current in the middle-low latitudes [25,47]. Through modelling the Sq current system at solar maximum and minimum, Takeda et al. [48] found that the ionospheric conductivity also exhibits a seasonal variation with larger conductivities generally occurring in the summer hemisphere. A comprehensive review of early studies of the Sq current system is provided by Chapman and Bartels [44]. The dominant characteristics of the Sq current system are its seasonal and solar cycle variations. Owing to differences in conductivity and winds, the Sq current system is not hemispherically symmetric and this feature exhibits a marked seasonal variation with the current intensity in the summer hemisphere being greater than the current intensity in the winter hemisphere. Walker et al. [10] found that a predominantly annual variation of Sq current is observed in the Northern Hemisphere with the peak value occurring near the June solstice. All these research results are consistent with the result of the ionospheric electric field in this paper. So the annual trend of ionospheric electric field is caused by Sq current system, which has the same seasonal variation that is high value in summer and low value in winter. Qian and Lin [4] pointed that the geo-electric field observed by ZD9A in fact has two parts, namely the telluric electric field and spontaneous electric field, based on the different field sources. The telluric electric field is the changing electric field generated by various field sources located outside the Earth and is distributed throughout the entire surface or larger regions. It is associated with the changing magnetic field in the geomagnetic field and has global or large regional characteristics. The spontaneous electric field is the relatively stable electric field formed on the Earth's surface by the subsurface media caused by various physical and chemical actions. It is made of the electric field 
by distribution of orebody, groundwater and various water systems, which generally has large changes in the horizontal and vertical gradient, in homogeneity, with strong local and even the local characteristics. Now it is difficult to completely separate the two parts. In general, the diurnal variation and its frequency represent the telluric electric field part in the data, which is homogenous with the ionospheric electric field and is correlated with the daily geomagnetic fluctuation $[4,22,23]$. As early as 1960, the long-term seasonal and solar cycle variability and significant day-to-day variability in the Sq current system are found [49]. So the annual variation of geo-electric field also reflects the part of telluric electric field, which has both annual and diurnal characteristics. So the annual variation characteristic of geo-electric field is also caused by Sq current system probably.

There is another phenomenon that needs to be discussed. The amplitude of data differs largely between ground-and space-based observation. In this paper, the amplitude of ionospheric electric field concentrated in several tens $\mathrm{mV} / \mathrm{m}$, whereas the amplitude of geo-electric field is from a few $\mathrm{mV} / \mathrm{km}$ to hundreds of $\mathrm{mV} / \mathrm{km}$. Vartosos et al. have reported their observations which the SES (seismic electric signals) occurred in certain regions with amplitude of up to $250 \mathrm{mV} / \mathrm{km}$ by $7-260 \mathrm{~h}$ prior to earthquakes using the VAN method [1-3,50]. Chmyrev et al. [7] analyzed the vertical component of quasi-static (DC) electric field Ez, based on the data recorded by INTERCOSMOS-BULGARIA-1300, and reported an anomalous increase of $3-7 \mathrm{mV} / \mathrm{m}$ in the quasi-static electric field. Zhang et al. [16] found that ULF electric field showed perturbations a few days before Wenchuan earthquake with amplitude of about $3-5 \mathrm{mV} / \mathrm{m}$, and the amplitude of ground electric field anomalies was from $3 \mathrm{mV} / \mathrm{km}$ to $100 \mathrm{mV} / \mathrm{km}$. Xiong et al. [51] and Sorokin et al. [52] pointed out that the anomalous signals of ground observation of electric field, were often in the range of a few tens $\mathrm{mV} / \mathrm{km}$ to a few hundred $\mathrm{mV} / \mathrm{km}$, which means that the amplitude of ground electromagnetic emissions was still far lower than that of space ones, even after consideration of the amplification in the atmosphere of DC/ULF electric field. Yu et al. [25-27] simulated ionospheric electric field which varies from less than $1 \mathrm{mV} / \mathrm{m}$ to several $\mathrm{mV} / \mathrm{m}$. Ye et al. [23] and Li et al. [36] researched the geo-electric field observed at stations in China and found that data in even very close stations can vary from several $\mathrm{mv} / \mathrm{km}$ to more than $100 \mathrm{mv} / \mathrm{km}$. It can be seen from these previous results that the amplitude of the geo-electric and ionospheric electric fields in this paper is in accordance with the observations performed with and without seismic activity. The electrodynamic model of the atmosphere-ionosphere coupling described in Sorokin et al. [40,41] and Sorokin and Chmyrev [53] also cannot be used to explain the different magnitudes of the electric field, because the electric field amplitude is attenuated largely during the propagation from the Earth's surface up to the ionosphere (around several tens of $\mathrm{V} / \mathrm{km}$ to tens of $\mathrm{mV} / \mathrm{m}$ ), which contradicts with the actual observation data in this paper. According to coupling mechanisms, the anomalous electric fields associated with earthquakes are mostly due to the abnormal electric field in the atmosphere above the Earth's surface. Such electric field is relatively large, especially during thunderstorm activity and other events occurred [53-55]. In this paper, the geo-electric field used is the electric field generated by an external field through the underground medium and the electric field induced by the medium itself. Then the amplitude of this electric field is of the order of a few hundred $\mathrm{mV} / \mathrm{km}$, which is different from the electric field intensity evaluated in electrodynamic model. In addition, it must be noted that in their theory of peroxy defects, Freund et al. [56] and Scoville et al. [57] claimed that stress activation of positive holes, a prerequisite for pre-earthquake phenomena, is efficient for earthquake hypocentres located in the upper to middle crust. This is the location of the geo-electric field studied here. Shen et al. [58] proposed a new mechanism where the magnetite aggregate in the crust could be a converter from thermal into electric during the process of earthquake 
preparation, namely, abnormal geo-electricity is caused by a thermoelectric mechanism. Based on the thermoelectric coefficient value tested in the experiments and on the thermoelectric and geo-electric theories the thermoelectric field was calculated. It was showed that the field intensity can reach $10^{-6} \mathrm{~V} / \mathrm{m} \sim 10^{-4} \mathrm{~V} / \mathrm{m}$. This model result is very consistent with the geo-electric anomalies detected by many earthquake monitoring. At the end, we have not explained the reason of the different amplitudes between ground- and space-based data observed in this paper, but this study shows that these amplitudes are reliable. Further research is needed to investigate this point.

\section{Conclusions}

For the ionospheric electric field, at $660 \mathrm{~km}$ altitude during night all over China, we have confirmed that there is obvious annual variation trend. We can also get the variation model with approximate sinusoidal.

For geo-electric field in some positions, there are similar or same annual variation trends with ionospheric electric field.

The synchronous, corresponding and similar significant annual variation trends of both ionospheric electric field and geo-electric field are identical at some locations, but the definite correlation between ionospheric electric field and geo-electric field everywhere is not true. Further researches on these phenomena are necessary and meaningful.

This research will hopefully help us to understand the nature of electric field in the ionosphere and on ground, and its penetration mechanism from ground into the ionosphere in case of catastrophic events occurring at the Earth's surface (earthquakes, tsunamis, hurricanes,...).

In this paper, we cannot measure the ionospheric electric field at a fix position and with uniform time intervals, so the results are a little bit biased. But as for the data available at the moment, the results in this paper are objective and effective. When DEMETER was launched in 2006, Zlotnicki et al. [59] had tried to monitor active faults and volcanoes using ground-based electromagnetic data combined with remote sensing based on DEMETER mission, but they did not get ideal results at that time. There are still a lot of work needed to be done, not only in LAI coupling, but also concerning the characteristic in normal conditions. A large-scale normalized electromagnetic observational network for detecting seismic precursors has been built in China. The CSES (China Seismo-Electromagnetic Satellite) had been launched in February 2018, which is proposed to be the first experimental satellite for China earthquake monitoring system from space $[60,61]$. More studies in this research field are meaningful.

A part of this work was done during the stay of Rui Yan in LPC2E, who expresses sincere thanks to Professor Jean-louis Pinçon for useful and fruitful discussions. The authors also express sincere thanks to Professor Q. Z. Ma for the advices of geo-electric field data processing and D. Pisa for advices about additional electric field calculation. This work is supported by the National Natural Science Foundation of China (41404058) and special fund for public welfare of Scientific Research Project of ICD, CEA (No.ZDJ2016-19). This work is mainly related to data recorded by the ICE of the microsatellite DEMETER that was operated by the French Centre National d'Etudes Spatiales (CNES) and the data measured by ZD9A which was operated by China Earthquake Networks Centre China Earthquake Administration (CEA). 
Publisher's Note The EPJ Publishers remain neutral with regard to jurisdictional claims in published maps and institutional affiliations.

\section{References}

1. P. Varotsos, K. Alexopoulos, Tectonophys. 110, 73 (1984)

2. P. Varotsos, K. Alexopoulos, Tectonophys. 110, 99 (1984)

3. P. Varotsos, K. Alexopoulos, Tectonophys. 136, 335 (1987)

4. J.D. Qian, Y.F. Lin, in Seismic electromagnetic observation techniques (in Chinese) (Seismological Press Beijing, 1995), pp. 222-239

5. X.B. Du, J.L. Xi, D.C. Tan, J.L. Zhao, J.D. Qian, Y.Q. Lu, J. Lu, Y.X. Tang, H.L. Kang, Y.F. Chen, D.Z. Wang, in Specification for the construction of seismic station Geoelectrical station part 2: Geoelectrical field observatory (The Seismology Trades Standard of the PRC DB/T 18.2-2006) (in Chinese) (Seismological Press, Beijing, 2006), pp. $1-13$

6. Q.Z. Ma, Acta Seismol. Sin. 30, 615 (2008)

7. V. Chmyrev, N. Isaev, S. Bilichenko, G. Stanev, Phys. Earth Planet. Inter. 57, 110 (1989)

8. M. Gousheva, R. Glavcheva, D. Danov, P. Anfelov, P. Hristov, Compt. Rend. Acad. Bulg. Sci. 58, 911 (2005)

9. X.M. Zhang, Z.M Zeren, M. Parrot, R. Battiston, J.D. Qian, X.H. Shen, Adv. Space Res. 47, 991 (2011)

10. S.N. Walker, V. Kadirkamanatan, O.A. Pokhotelov, Ann. Geophys. 31, 1567 (2013)

11. X.M. Zhang, X.H. Shen, S.F. Zhao, L. Yao, X.Y. Ouyang, J.D. Qian, J. Asian Earth Sci. 79, 42 (2014)

12. S. Bhattacharya, S. Sarkar, A.K. Gwal, M. Parrot, Curr. Sci. 93, 41 (2007)

13. J. Liu, X.B. Du, J. Zlotnicki, Y.Y. Fan, Z.H. An, T. Xie, G.L. Zheng, D.C. Tan, J.Y. Chen, Chin. J. Geophys. 54, 828 (2011)

14. Z.H. An, X.B. Du, Y.Y. Fan, J. Liu, D.C. Tan, J.Y. Chen, T. Xie, Chin. J. Geophys. (in Chinese) 54, 145 (2011)

15. X.M. Zhang, X.H. Shen, Y.Q. Miao, Int. J. Geophys. 1, 693 (2011)

16. X.M. Zhang, H.R. Chen, J. Liu, X.H. Shen, Y.Q. Miao, X.B. Du, J.D. Qian, Adv. Space Res. 50, 85 (2012)

17. V. Sorokin, M. Hayakawa, Mod. Appl. Sci. 7, 1913 (2013)

18. V. Chmyrev, A. Smith, D. Kataria, B. Nesterov, C. Owen, P. Sammonds, V. Sorokin, F. Vallianatos, Adv. Space Res. 52, 1135 (2013)

19. S. Pulinets, D. Ouzounov, A. Karelin, D. Davidenko, in Lithosphere - Atmosphere Ionosphere - Magnetosphere - Coupling (LAIMC) - a Concept for Pre-earthquake Signals Generation (AGU book, 2017), pp. 79-98

20. F.T. Freund, I.G. Kulahci, G. Cyr, J.L. Ling, M. Winnick, J. Tregloan-Reed, M.M. Freund, J. At. Sol.-Terr. Phys. 71, 1824 (2009)

21. R. Yan, L.W. Wang, S.Z. Zhang, Z. Hu, X.G. Zhang, D.P. Liu, X. Zhu, Y. Zhang, Chin. J. Geophys. (in Chinese) 56, 1334 (2013)

22. T. Mogi, Y. Tanaka, D.S. Widarto, E.M. Arsadi, N.T. Puspito, T. Nagao, W. Kanda, S. Uyeda, Earth Planets Space 52, 245 (2000)

23. Q. Ye, Master thesis Lanzhou Institute of Seismology, China Earthquake Administration, 2006

24. T.F. Cui, X.B. Du, Q. Ye, J.Y. Chen, J.J. Wang, Z. H. An, Y.Y. Fan, J. Liu, Chin. J. Geophys. 56 (2013)

25. T. Yu, Ph.D. thesis Wuhan Institute of Physics and Mathematics, Chinese academy of Sciences, 2003

26. T. Yu, W.X. Wan, L.B. Liu, Sci. Chin. Phys. Mech. 46, 23 (2003)

27. T. Yu, W.X. Wan, L.B. Liu, J. H. Lei, X. Y Li, Chin. J. Spac. Sci. 24, 183 (2004)

28. J.L. Xi, J.L. Zhao, Y.Q Wang, Appl. Electron. Tech. 25, 30 (1999)

29. J.L. Xi, J.L. Zhao, Y.Q Wang, L.W. Wang, Y.D. Li, Earthquake 22, 67 (2002) 
30. M. Parrot, Planet. Space Sci 54, 411 (2006)

31. J.J. Berthelier, M. Godefroy, F. Leblanc, E. Seran, D. Peschard, P. Gilbert, J. Artru, Planet. Space Sci. 54, 487 (2006)

32. D. Lagoutte, J.Y. Brochot, D. Carvalho, L. Madrias, M. Parrot, LPCE-CNRS Report, DMT-SP-9-CM-6054-LPC-3.3 (2006)

33. X.M. Zhang, J.D. Qian, X.H. Shen, J. Geophys. Res. 119, 305 (2014)

34. D. Pisa, O. Santolik, M. Parrot, Pre-processing of the ULF Waveform Fluctuations Above Seismic Active Regions Observed by DEMETER, f-2, in Proceedings of WDS'11, Part II (2011) pp. 73-78

35. J.Z. Ma, L. Zhang, H.P. Guan, S. Tian, J. Ma, Seismol. Geomag. Obs. Res. 31, 486 (2010)

36. W. Li, Q.Z. Ma, G.Y. Wang, Earthquake Res. Chin. 30, 91 (2014)

37. D.C. Tan, J.L. Zhao, J.L. Xi, X.B. Du, J.M. Xu, Chin. J. Geophys. 53, 544 (2010)

38. V.V. Hegai, V.P. Kim, L.I. Nikiforova, J. Earthquake Predic. Res. 6, 584 (1997)

39. S.A. Pulinets, K.A. Boyarchuk, V.V. Hegai, V.P. Kim, Adv. Space Res. 26, 1209 (2000)

40. V.M. Sorokin, V.M. Chmyrev, A.K. Yaschenko, J. Atmos. Sol. Terr. Phys. 63, 1681 (2001)

41. V.M. Sorokin, V.M. Chmyrev, A.K. Yaschenko, J. Atmos. Sol. Terr. Phys. 67, 1259 (2005)

42. V.M. Chmyrev, V.M. Sorokin, J. Atmos. Sol. Terr. Phys. 72, 992 (2010)

43. N.L. Xiong, C.C. Tang, X.J. Li, The Ionosphere Physics Probability (in Chinese) (Wuhan University Press, Wuhan, 1997)

44. S. Chapman, J. Bartels, in Geomagnetism (Clarendon Press, Oxford, 1940), Vols. 1 and 2, p. 130

45. S. Matsushita, in Physics of geomagnetic phenomena 2 volumes (International Geophysics Series), edited by S. Matsushita, W.H. Campbell (Academic Press, New York and London, 1967), Vol. 11

46. A.D. Richmond, Pure Appl. Geophys. 47, 413 (1989)

47. Y. Kamid, W. Baumjohann, Magnetosphere-ionosphere coupling (Springer, Berlin, 1993)

48. M. Takeda, Y. Yamada, T. Araki, J. Atmos. Terr. Phys. 48, 277 (1986)

49. M. Hasegawa, J. Geophys. Res. 65, 1437 (1960)

50. P.A. Varotsos, N.V. Sarlis, E.S. Skordas, Phys. Chem. Earth 31, 189 (2006)

51. H. Xiong, Acta Seismol. Sin. 5, 407 (1992)

52. V.M. Sorokin, A.K. Yaschenko, V.M. Chmyrev, M. Hayakawa, Nat. Hazards Earth Syst. Sci. 5, 661 (2005)

53. V.M. Sorokin, V.M. Chmyrev, Atmosphere-ionosphere electrodynamic coupling, in The Atmosphere and Ionosphere: Dynamics, Processes and Monitoring, edited by V.L. Bychkov, G.V. Golubkov, A.I. Nikitin (Springer, 2010), pp. 97-146

54. C.G. Park, M. Dejnakarintra, J. Geophys. Res. 78, 6623 (1973)

55. C.G. Park, J. Geophys. Res. 81, 168 (1976)

56. F.T. Freund, M.M. Freund, J. Asian Earth Sci. 114, 373 (2015)

57. J. Scoville, J. Sornette, F.T. Freund, J. Asian Earth Sci. 114, 338 (2015)

58. J.F. Shen, X.H. Shen, Q. Liu, J. Miner. Pet. 30, 21 (2010)

59. J. Zlotnicki, J.L. LeMou,l, R. Kanwar, P. Yvetot, G. Vargemezis, P. Menny, F. Fauquet, Planet. Space Sci. 54, 541 (2006)

60. L.W. Wang, X.H. Shen, Y. Zhang, X.G. Zhang, Z. Hu, R. Yan, S.G. Yuan, X.H. Zhu, Acta Seismol. Sin. 38, 376 (2016)

61. X.H. Shen, X.M. Zhang, S.G. Yuan, L.W. Wang, J.B. Cao, J.P. Huang, X.H. Zhu, P. Piergiorgio, J.P. Dai, Sci. Chin. Technol. 61, 634 (2018) 